\title{
REACTIVITY OF YOUNG CHARS VIA ENERGETIC DISTRIBUTION MEASUREMENTS
}

J.M. CALO (Principal Investigator), L.-H. ZHANG, W.G. RACHEL, and W.D. LILLY

Division of Engineering

BROWN UNIVERSITY

Providence, Rhode Island 02912

Quarterly Technical Progress Report

15 March 1991 - 15 June 1991

Prepared for:

U.S. DEPARTMENT OF ENERGY

Pittsburgh Energy Technology Center

Pittsburgh, Pennsylvania 15236

["US/DOE Patent Clearance is not required prior to the publication of this document."] 


\section{Disclaimer}

'This report was prepared as an account of work sponsored by the United States Government. Neither the United States, nor the United States Department of Energy, nor any of their employees, makes any warranty, express or implied, or assumes any legal responsibility for the accuracy, completeness, or usefulness of any information, apparatus, product, or process disclosed, or represents that its use would not infringe privately owned rights. 


\section{SUMMARY}

In this report, we present some preliminary work performed on the effect of $\mathrm{CO}_{2}$ partial pressure on temperature programmed desorption spectra from $\mathrm{CO}_{2}$-oxidized chars.

\section{The following was accomplished during the reporting period:}

- Temperature programmed desorption (TPD) experiments were conducted on oxidized resin and Wyodak coal char samples gasified under varying different $\mathrm{CO}_{2}$ partial pressures.

- The following observations were made:

- $\mathrm{CO}_{2}$ partial pressure can be an important factor affecting TPD spectra.

- Generally, the total amount of surface oxygen desorbed as $\mathrm{CO}$ and $\mathrm{CO}_{2}$ increases with $\mathrm{CO}_{2}$ partial pressure during gasification for both resin char and Wyodak coal char.

- The total amount of oxygen desorbed is also a function of gasification temperature. Apparently, the higher the gasification temperature, the more $\mathrm{CO}$ and $\mathrm{CO}_{2}$ are desorbed. As an example, for 0.33 atm $\mathrm{CO}_{2}$ partial pressure, the peak $\mathrm{CO}$ desorption rates are 0.17 $\mathrm{mmole} / \mathrm{g} / \mathrm{min}$ and $0.13 \mathrm{mmole} / \mathrm{g} / \mathrm{min}$, corresponding to gasification temperature $1223 \mathrm{~K}$ and $1173 \mathrm{~K}$.

\section{Plans for the next reporting period include:}

- Experiments concerning the effects of "inert," diluent gases on char reactivity in $\mathrm{CO}_{2}$ and $\mathrm{O}_{2}$ will be conducted.

- Reactivity measurements, as well as corresponding TPD spectra, will be obtained in order to establish a mechanistic basis for the operative phenomena.

- The TPD reactor system will adapted for subatmospheric/vacuum operation in order to enhance the sensitivity of the system and explore the nature of certain features in the TPD spectra which have: been attributed to secondary interaction effects. 


\subsection{PROJECT BACKGROUND}

The correlation and prediction of kinetic rates and mechanisms of the reactions of gas phase species with coal chars represent a difficulty undertaking under the best of circumstances. Solid phase heterogeneity and impurities, complex pore structure, transport limitation, and evoluation of active surface represent just a few of the well known problems. Because of this complexity, this largely remains an unresolved but, nevertheless, important problem affecting niany aspects of coal utilization. The only techniques available until now were empirical correlations which may be useful for a single coal, or, at best, a special subset of coals, but are by no means global because they are not fundamental. This severely constrains the predictive capability of such methods.

The temperature programmed desorption (TPD) has become a standard technique for investigating the physico-chemical state of adsorbed species on surfaces. The predecessor of TPDtype methods was the flash filament technique of Redhead(1962), whereby gases adsorbed on wire filaments are rapidly desorbed upon rapid heating in an ultrahigh vacuum. This teclinique was subsequently adapted to catalytic surfaces(e.g., see Cvetanovic and Amenomiya, 1967, 1971). Experimental method and interpretation of TPD spectra for well defined crystalline surfaces have been reviewed by King(1975).

TPD spectra usually consist of one or more peaks. The shapes of the peaks and the position of the peak maxima with respect to temperature are related in a fundamental manner to the desorption process, and, therefore, provide basic information regarding the energetics of the desorbed species.

As a result of previous work, we accomplished what amounts to a significant breakthrough in this long-standing, important problem. In short, we have developed what we believe to be the very first a priori prediction technique for the gasification reactivity of coal char. With this method the. gasification reactivity of a coal char as a function of temperature can be predicted from a single TPD experiment following mild gasification at a single temperature (Calo et al., 1989; Hall and Calo, 1990a). This approach has been demonstrated for $\mathrm{CO}_{2}$ gasification of coal chars where the gasification reactivity is controlled by the thermal desorption of oxygen surface complexes formed 
during gasification. This approach may be extended to other oxidant species, such as steam, and carbon-hydrogen complexes for hydrogen gasification as well.

The purpose for the current project is to investigate the effect of $\mathrm{CO}_{2}$ partial pressures on the resultant energetic distribution of oxygen surface complex, and to obtain the TPD spectra for resin char and wyodak samples gasified in various diluent gases and $\mathrm{O}_{2}$ or $\mathrm{CO}_{2}$ mixture.

\subsection{EXPERIMENTAL}

\subsection{The TPD Apparatus and Methods.}

The TPD apparatus consists of three principal parts:

(1) The gas flow/metering system which provides an inert carrier gas to convect away desorbed species from the vicinity of the char samples;

(2) The reactor where the sample is subjected to the controlled heating program for desorption of surface species; and

(3) The detector (quadrupole mass spectrometer) for evolved species.

The experimental details are as follows. Char oxidation/gasification was performed in a TGA apparatus in 0.1 MPa total pressure of oxidant gas at specific temperatures. Following cooling to room temperature in the TGA apparatus, the samples were transferred to the TPD reactor.

The TPD reactor is constructed from a high-purity silica tube, $1-\mathrm{cm}$ inside diameter, within which a close-fitting, circular silica sinter is used to support the sample. Ultrahigh purity helium carrier gas is passed over the sample in downflow. Heating is accomplished electrically via nichrome wire wrapped around the outside of the silica tube, powered by a high current variable transformer. The heating rate is controlled by a microcomputer.

Detection of desorbed species is accomplished with a quadrupole mass spectrometer (MS) which samples a small portion of the carrier flow. A simple programmer was developed which provides the DC levels required to automatically switch the mass spectrometer among four masses during the course of a TPD experiment. The MS output is fed to a microcomputer which also provides for multiple species detection via mass programming. For the current application, normally only masses $\mathrm{m} / \mathrm{e}=28$ and 44 , corresponding to $\mathrm{CO}$ and $\mathrm{CO}_{2}$, respectively, were 
monitored. The electron energy in the mass spectrometer ionizer was set to $\sim 25 \mathrm{~V}$ in order to eliminate cracking of $\mathrm{CO}_{2}$ to $\mathrm{CO}$ upon electron impact. In this manner, the two measured peak intensities reflect contributions from the parent species only.

The mass spectrometer was calibrated prior to each TPD run using $50 / 50 \mathrm{~mol} \% \mathrm{CO} / \mathrm{CO}_{2}$ mixture in order to determine relative species sensitivity. The MS signals were converted to an absolute basis via calibration with a series of pulse injections of calibration gas using a syringe, conducted in exactly the same fashion as the TPD experiments. The levels of the two peaks were recorded and the background at each peak was subtracted from these values. The background levels at $M / e=28$ and 44 were measured before and after each calibration, and were usually considerably less than the values measured with the calibration gas.

\subsection{General Experimental Procedures.}

The experiment procedure for a typical TPD experiment was as follows:

(1) The char sample was placed in a quartz sample bucket in the TGA apparatus. It was then thermally cleaned by heating in ultrahigh purity helium to a temperature of $1000^{\circ} \mathrm{C}$, and holding at this temperature for approximately $20 \mathrm{~min}$. The sample was then cooled to room temperature in ultrahigh purity helium.

(2) The sample was then heated to the desired chemisorption/gasification temperature and the oxidant gas (e.g., $\mathrm{O}_{2}, \mathrm{CO}_{2}$ or other gas mixture) was introduced. The desired temperature was then maintained until a predetermined time or burn-off achieved.

(3) A small sample of the oxidized char was then transferred to the TPD apparatus, and the helium purge gas flow was initiated.

(4) The mass spectrometer was calibrated prior to each experiment, as indicated above.

(5) The sample was then heated in ultrahigh purity helium carrier gas at the desired heating rate to an ultimate temperature (usually $1100-1150^{\circ} \mathrm{C}$ ), and the desorption rates $\mathrm{CO}$ and $\mathrm{CO}_{2}$ were measured using the MS. The temperature and the analog output from the MS were digitized and recorded in a data file on a microcomputer. 


\subsection{EFFECTS OF $\mathrm{CO}_{2}$ PARTIAL PRESSURE}

As a result of previous work, we established the relationship between $\mathrm{CO}_{2}$ reactivity at one atmosphere and TPD spectra of the oxygen surface complexes responsible (Calo et al., 1989). In order to extend this knowledge to the understanding of steam gasification and reactivity, the behavior of $\mathrm{CO}_{2}$ reactivity as a function of partial pressure must first be firmly established. The TPD experiments have been performed to investigate the effects of $\mathrm{CO}_{2}$ partial pressure on the resultant energetic distribution of oxygen surface complexes.

\subsection{Experimental.}

The chars used in the current experiments were produced from: (1) subbituminous Wyodak coal samples, obtained from the Argonne premium Coal Sample Bank; and (2) phenolformaldehyde resin, prepared in our own laboratory (Calo et al., 1989). The samples were carbonized in a tube furnace at $1000^{\circ} \mathrm{C}$ for $2 \mathrm{~h}$. The resultant chars were sieved and those particles with sizes between -16 to +100 mesh were used for the oxidation/gasification runs. These samples were gasified in a Cahn 113 microbalance thermogravimetric analysis (TGA) system. All runs were performed at a total pressure of one atmosphere. The variation of $\mathrm{CO}_{2}$ partial pressure was accomplished by dilution with ultrahigh purity helium. The resultant range of $\mathrm{CO}_{2}$ partial pressure was 0.018 atm to $1 \mathrm{~atm}$, and all samples were burned-off to about $5 \%$ mass loss.

A small amount of oxidized sample $(\sim 20 \mathrm{mg})$ was then transferred to the TPD apparatus. The sample was dried at $100^{\circ} \mathrm{C}$ for about 10 minutes to eliminate any $\mathrm{H}_{2} \mathrm{O}$ absorbed from sir prior to the TPD run. The heating rate was $100 \mathrm{~K} / \mathrm{min}$ to an ultimate temperature of $1423 \mathrm{~K}$ for every sample. The temperature and the analog output from the MS were recorded. The desorption rates for $\mathrm{CO}$ and $\mathrm{CO}_{2}$ were determined by means of data from calibration experiment.

\subsection{Results and Discussion.}

TPD spectra from the $5 \%$ gasified resin char (in 1 atm $\mathrm{CO}_{2}$ and helium mixture, or pure $\mathrm{CO}_{2}$ at $1173 \mathrm{~K}$ ) are presented in Figures 1 and 2. Comparison is made among three samples with $\mathrm{CO}_{2}$ 
partial pressures of $0.062 \mathrm{~atm}, 0.33 \mathrm{~atm}$, and $1 \mathrm{~atm}$ respectively. It can be seen that the $\mathrm{CO}$ evolution consists of a peak centered $c a .1250 \mathrm{~K}$ for all three cases and that the total amount of $\mathrm{CO}$ desorbed is similar at 1.0 and 0.33 atm, and significantly less for the $0.062 \mathrm{~atm}$ case. The corresponding reactivities for these samples are presented in Figure 3. As shown, the reactivities of the the 1.0 and 0.33 atm are also quite similar, with that at 1.0 atm being slightly less. This behavior is as yet unexplained (cf. DE-FG22-90PC90307-2), but the TPD spectra confirm this behavior. That is, the amount of surface complex is similar for these two partial pressures, and considerably less for the low pressure sample. The peak CO desorption rate is $0.13 \mathrm{mmole} / \mathrm{g} / \mathrm{min}$ for $0.016 \mathrm{~atm} \mathrm{CO}_{2}$ partial pressure, $0.17 \mathrm{mmole} / \mathrm{g} / \mathrm{min}$ for $0.33 \mathrm{~atm} \mathrm{CO}_{2}$ partial pressure, and 0.19 $\mathrm{mmole} / \mathrm{g} / \mathrm{min}$ for pure $\mathrm{CO}_{2}$. As shown in Figure 2, the $\mathrm{CO}_{2}$ desorption rate also increases with $\mathrm{CO}_{2}$ partial pressure, but the amount of increase is not as significant as for the $\mathrm{CO}$ desorbed.

Figures 3 and 4 compare the effects of varying $\mathrm{CO}_{2}$ partial pressure on $100 \mathrm{~K} / \mathrm{min}$ TPD spectra for Wyodak gasified at 1 atm at 1203K; while Figures 5 and 6 are similar spectra for Wyodak gasified at $1223 \mathrm{~K}$. The ultimate temperature attained in these TPD runs was $1373 \mathrm{~K}$. As can be seen, there are certain features common to all the spectra, with three desorption peaks for $\mathrm{CO}_{2}$ centered $c a .600 \mathrm{~K}, 825 \mathrm{~K}$, and $950 \mathrm{~K}$, and more than one desorption peak for $\mathrm{CO}$, the principal one of which is centered $c a .1250 \mathrm{~K}$, and another feature which appears to peak at a temperature higher than $1373 \mathrm{~K} . \mathrm{CO}_{2}$ partial pressure has a similar effect on the TPD spectra for the Wyodak coal char samples as it did for the resin char samples.

These results also show that the total amount of oxygen desorbed is a function of gasification temperature. Apparently, the higher the gasification temperature, the more $\mathrm{CO}$ and $\mathrm{CO}_{2}$ are desorbed. As an example, as shown in Figures 7 and 8, for 0.33 atm $\mathrm{CO}_{2}$ partial pressure, the peak $\mathrm{CO}$ desorption rates are $0.17 \mathrm{mmole} / \mathrm{g} / \mathrm{min}$ and $0.13 \mathrm{mmole} / \mathrm{g} / \mathrm{min}$, corresponding to gasification temperature $1223 \mathrm{~K}$ and $1173 \mathrm{~K}$.

\subsection{Conclusions.}

It was found that the $\mathrm{CO}_{2}$ partial pressure can be an important factor affecting TPD spectra. Generally, the total amount of surface oxygen desorbed as $\mathrm{CO}$ and $\mathrm{CO}_{2}$ increases with $\mathrm{CO}_{2}$ partial pressure during gasification for both resin char and Wyodak coal char. 


\subsection{PLANS FOR THE NEXT REPORTING PERIOD}

- Experiments concerning the effects of "inert," diluent gases on char reactivity in $\mathrm{CO}_{2}$ and $\mathrm{O}_{2}$ will be conducted.

- Reactivity measurements, as well as corresponding TPD spectra, will be obtained in order to establish a mechanistic basis for the operative phenomena.

- The TPD reactor system will adapted for subatmospheric/vacuum operation in order to enhance the sensitivity of the system and explore the nature of certain features in the TPD spectra which have been attributed to secondary interaction effects.

- Due to the relatively low resultant amounts of oxygen complex found on the char sample surfaces following gasification in $\mathrm{CO}_{2}$, it is neccessary to improve the sensitivity of the resultant TPD spectra. This can be achieved by either increasing the size of the oxidized sample, and/or operating the programmed desorption at lower pressures where nearly all of the desorbed gases can be sampled directlty into the mass spectrometer.

- In addition, low pressure operating capability will enable the exploration of secondary interaction effects in the TPD spectra which may be related to absolute pressure during desorption.

\section{LITERATURE REFERENCES}

Britten, J.A., Falconer, J.L., and Brown, L.F. Carbon 23, 627 (1987).

Calo, J.M. and P.J. Hall, ACS Div. Fuel Chem. Prepr. 34, No. 1, 71 (1989).

Cvetanovic', R.J., and Y. Amenomiya, Advan. Catal. 17, 103 (1967).

Cvetanovic', R.J., and Y. Amenomiya, Cat. Rev. 6, 21 (1972).

Goodman, F.O. J. Cat. 36, 159 (1975).

Hall, P.J., and Calo, J.M., "The Prediction/Correlation of $\mathrm{CO}_{2}$ Gasification Reactivity From Desorption Spectra," in preparation, 1990a.

Hudgins, R.R., and P.L. Silveston Cat. Rev.-Sci. Eng.3, 167 (1975).

King (1975), D.A., Surface Science 47, 384 (1975).

Prentz, L., M.S. Thesis, Pennsylvania State University, 1959.

Redhead, P.A.,Vacuum 12, 203 (1962).

Rhodey, W.G., P.M. Reilly, P.L. Silveston, and R.R. Hudgins J. Cat. 42, 312 (1976).

Walker, P.L., Jr., L. Prentz, D.L. Biederman, and F.J. Vastola Carbon 15, 165 (1977). 


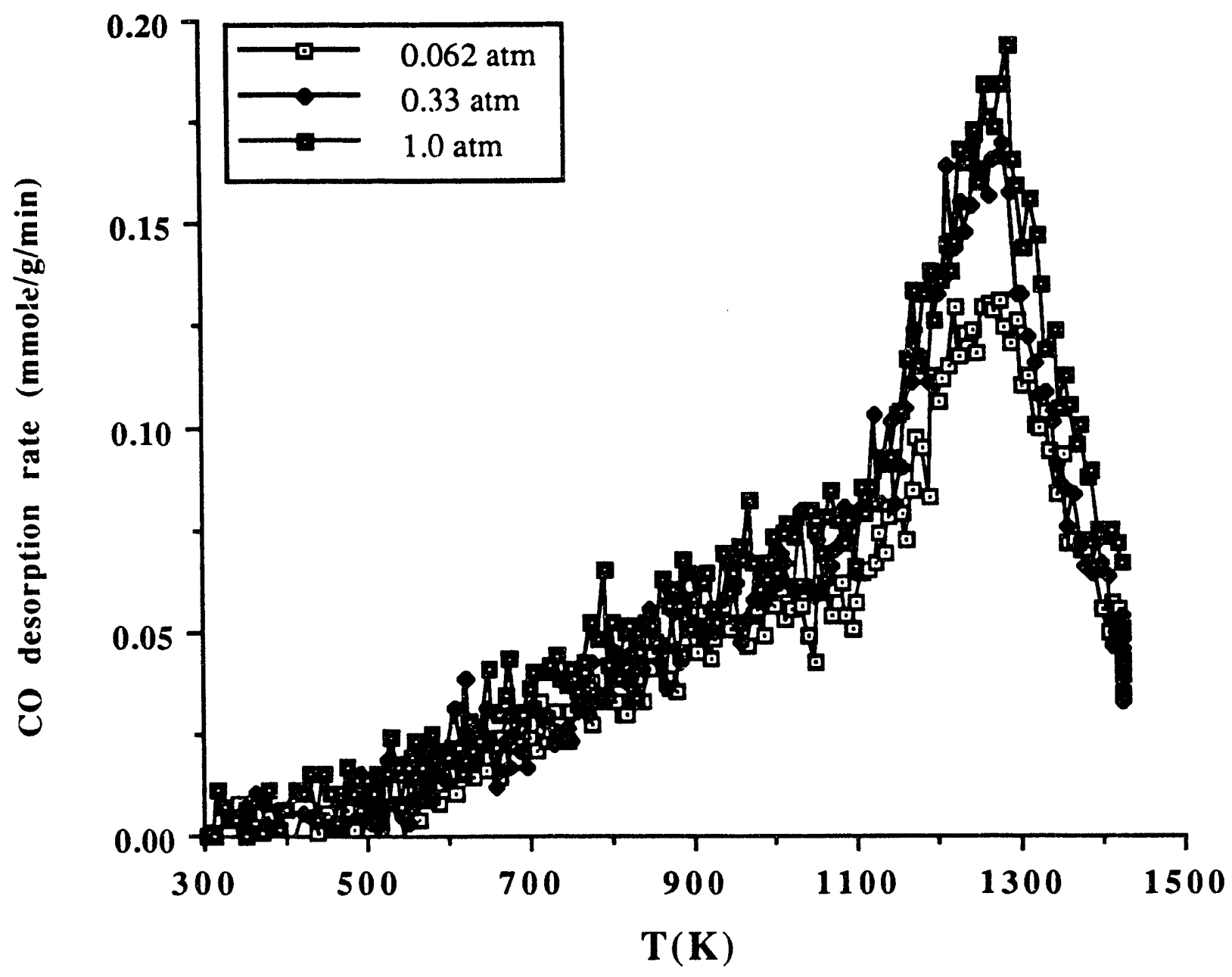

Figure 1. $100 \mathrm{~K} / \mathrm{min} \mathrm{CO}$ TPD spectra from resin char gasified at $1173 \mathrm{~K}$ as a function of $\mathrm{CO}_{2}$ partial pressure at a total pressure of $0.1 \mathrm{MPa}$. Ultrahigh purity helium was used as the diluent gas. 




Figure 2. $100 \mathrm{~K} / \mathrm{min} \mathrm{CO}_{2}$ TPD spectra from resin char gasified at $1173 \mathrm{~K}$ as a function of $\mathrm{CO}_{2}$ partial pressure at a total pressure of $0.1 \mathrm{MPa}$. Ultrahigh purity helium was used as the diluent gas. 


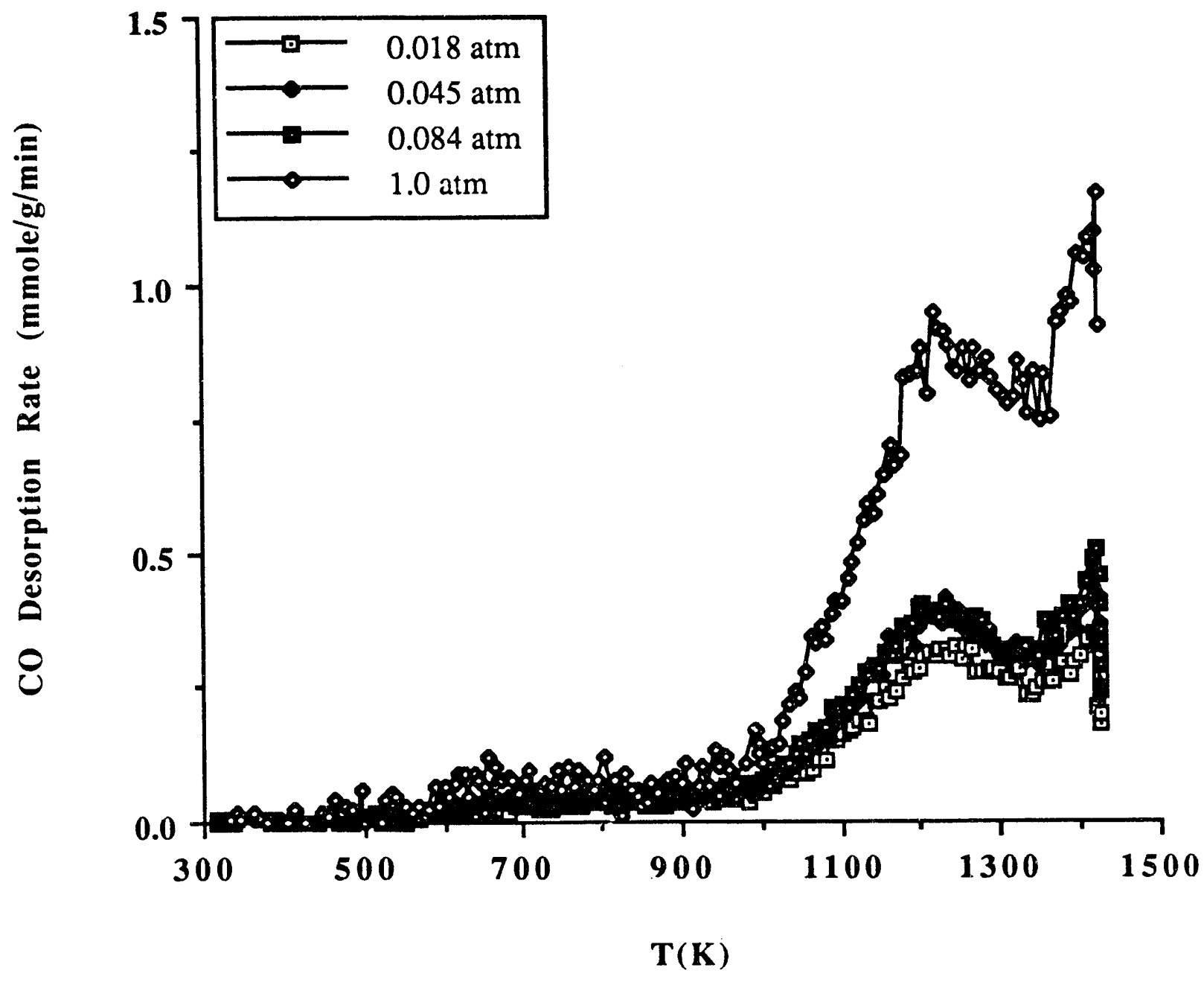

Figure 3. $100 \mathrm{~K} / \mathrm{min}$ CO TPD spectra from Wyodak coal char gasified at $1023 \mathrm{~K}$ as a function of $\mathrm{CO}_{2}$ partial pressure at a total pressure of $0.1 \mathrm{MPa}$. Ultrahigh purity helium was used as the diluent gas. 


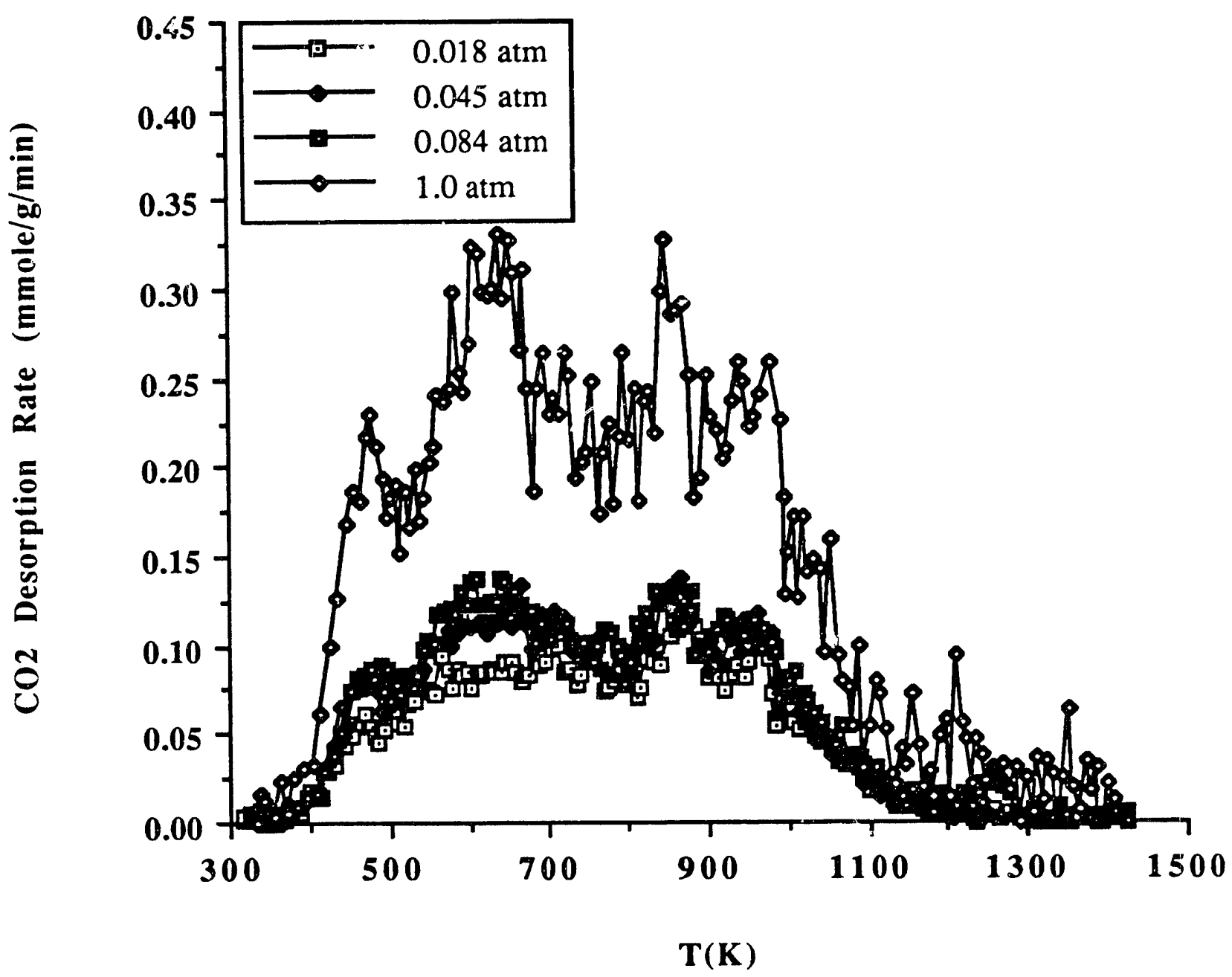

Figure 4. $100 \mathrm{~K} / \mathrm{min} \mathrm{CO}_{2}$ TPD spectra from Wyodak coal char gasified at $1023 \mathrm{~K}$ as a function of $\mathrm{CO}_{2}$ partial pressure at a total pressure of $0.1 \mathrm{MPa}$. Ultrahigh purity helium was used as the diluent gas. 


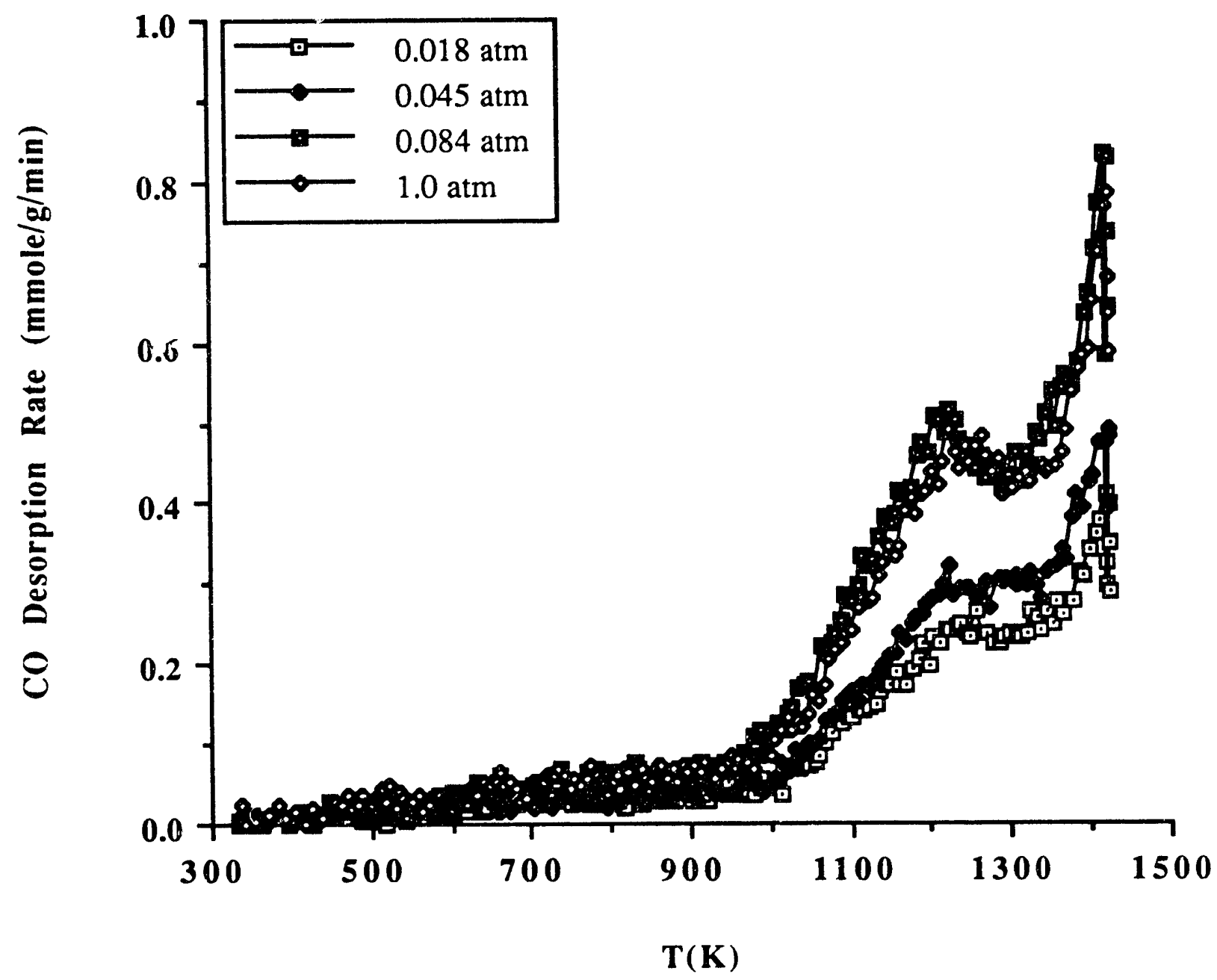

Figure 5. $100 \mathrm{~K} / \mathrm{min}$ CO TPD spectra from Wyodak coal char gasified at $1223 \mathrm{~K}$ as a function of $\mathrm{CO}_{2}$ partial pressure at a total pressure of $0.1 \mathrm{MPa}$. Ultrahigh purity helium was used as the diluent gas. 


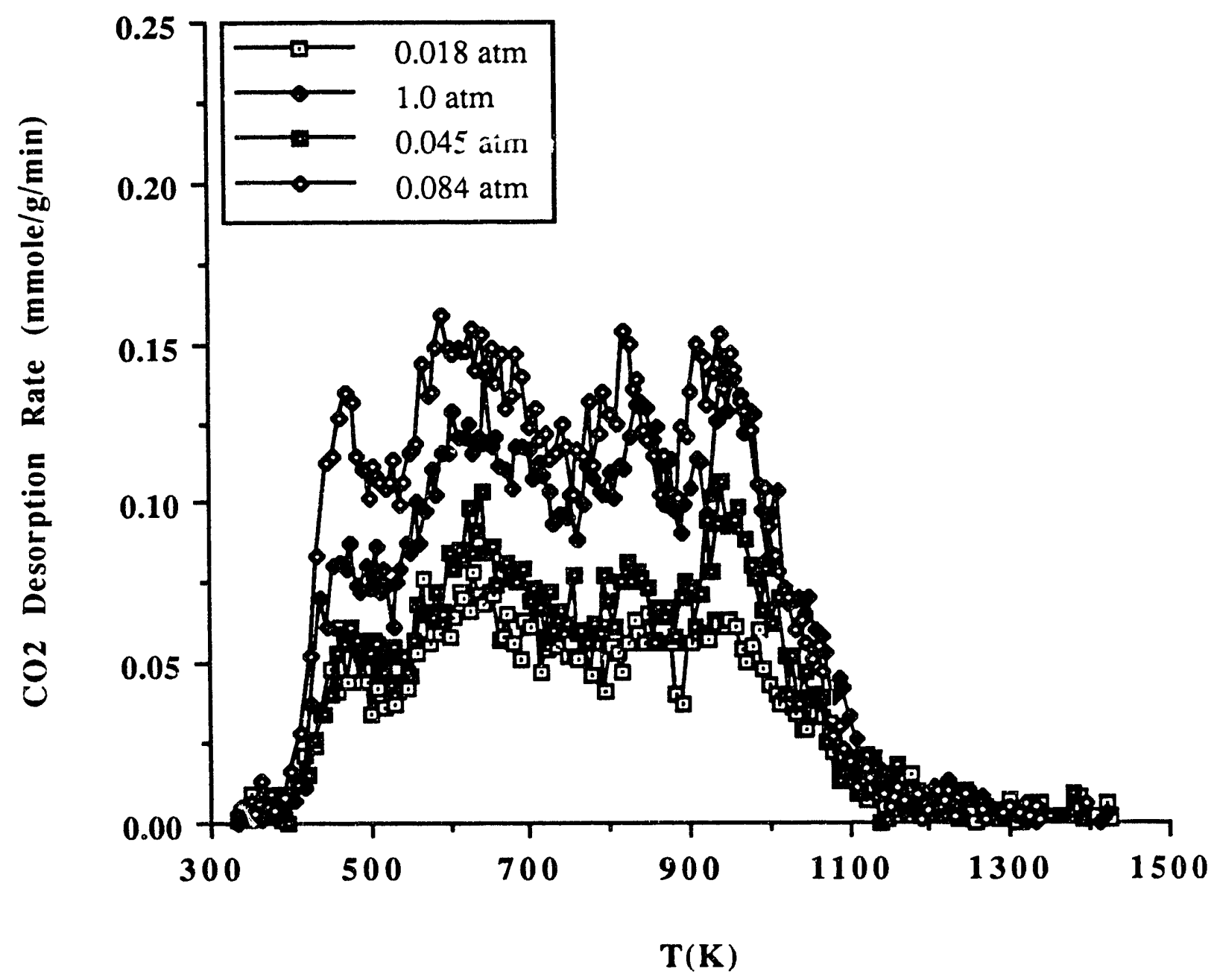

Figure 6. $100 \mathrm{~K} / \mathrm{min} \mathrm{CO}_{2}$ TPD spectra from Wyodak coal char gasified at $1223 \mathrm{~K}$ as a function of $\mathrm{CO}_{2}$ partial pressure at a total pressure of $0.1 \mathrm{MPa}$. Ultrahigh purity helium was used as the diluent gas. 


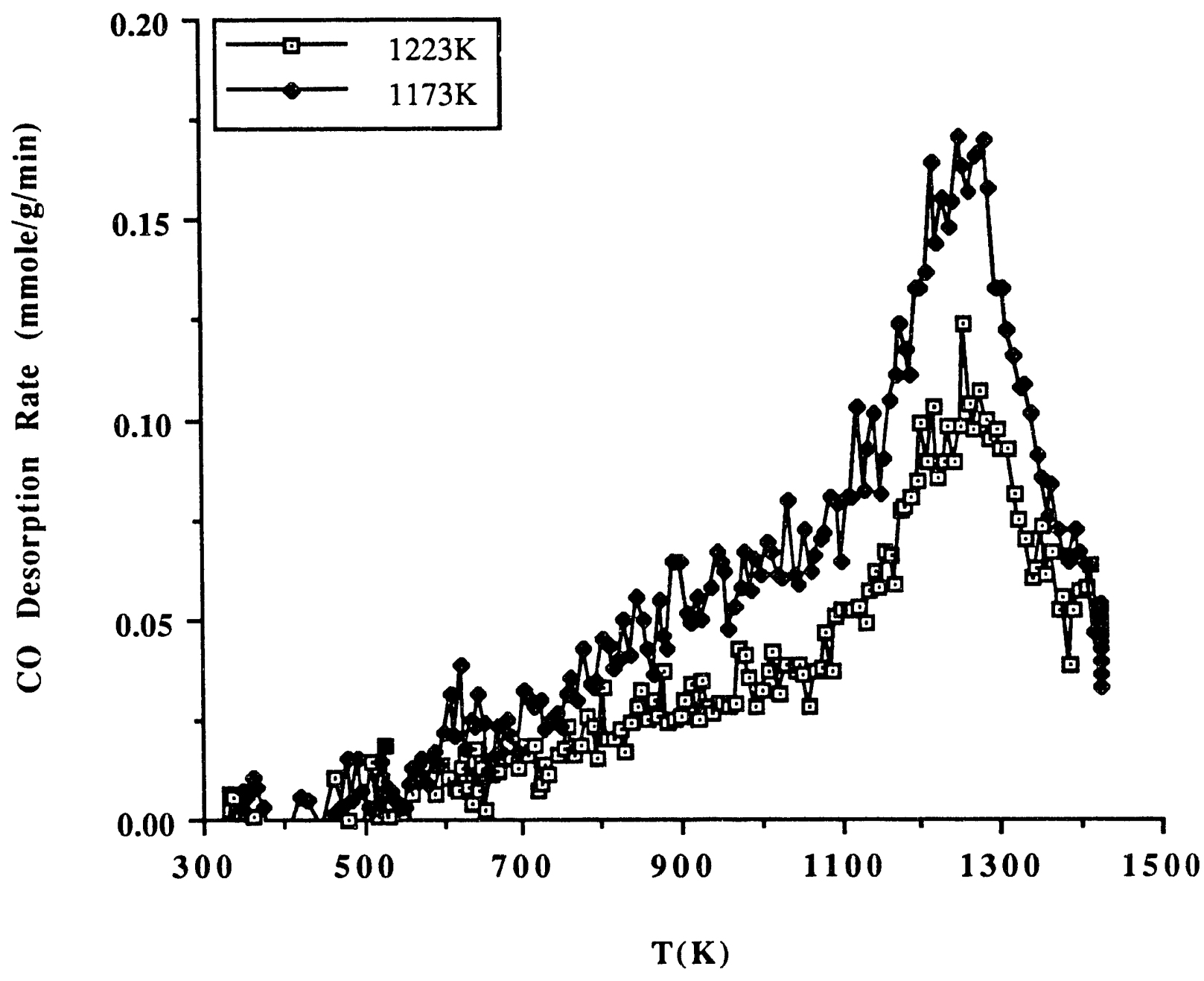

Figure 7. $100 \mathrm{~K} / \mathrm{min}$ CO TPD spectra from resin char gasified to $5 \%$ burn-off in $0.33 \mathrm{~atm}$ of $\mathrm{CO}_{2}$ at a total pressure of $0.1 \mathrm{MPa}$, at the two temperatures indicated. Ultrahigh purity helium was used as the diluent gas. 


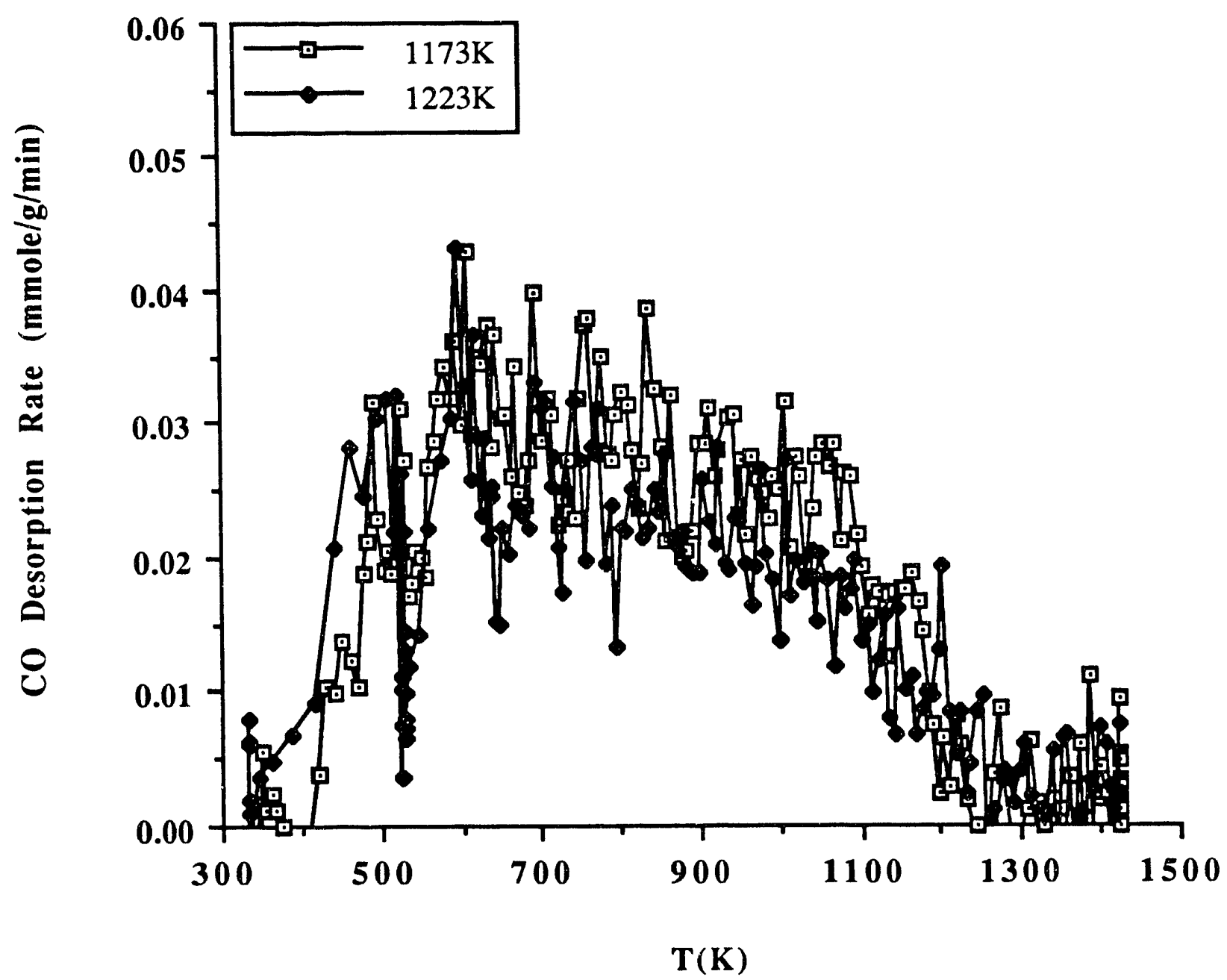

Figure 8. $100 \mathrm{~K} / \mathrm{min} \mathrm{CO}_{2}$ TPD spectra from resin char gasified to $5 \%$ burn-off in $0.33 \mathrm{~atm}$ of $\mathrm{CO}_{2}$ at a total pressure of $0.1 \mathrm{MPa}$, at the two temperatures indicated. Ultrahigh purity helium was used as the diluent gas. 

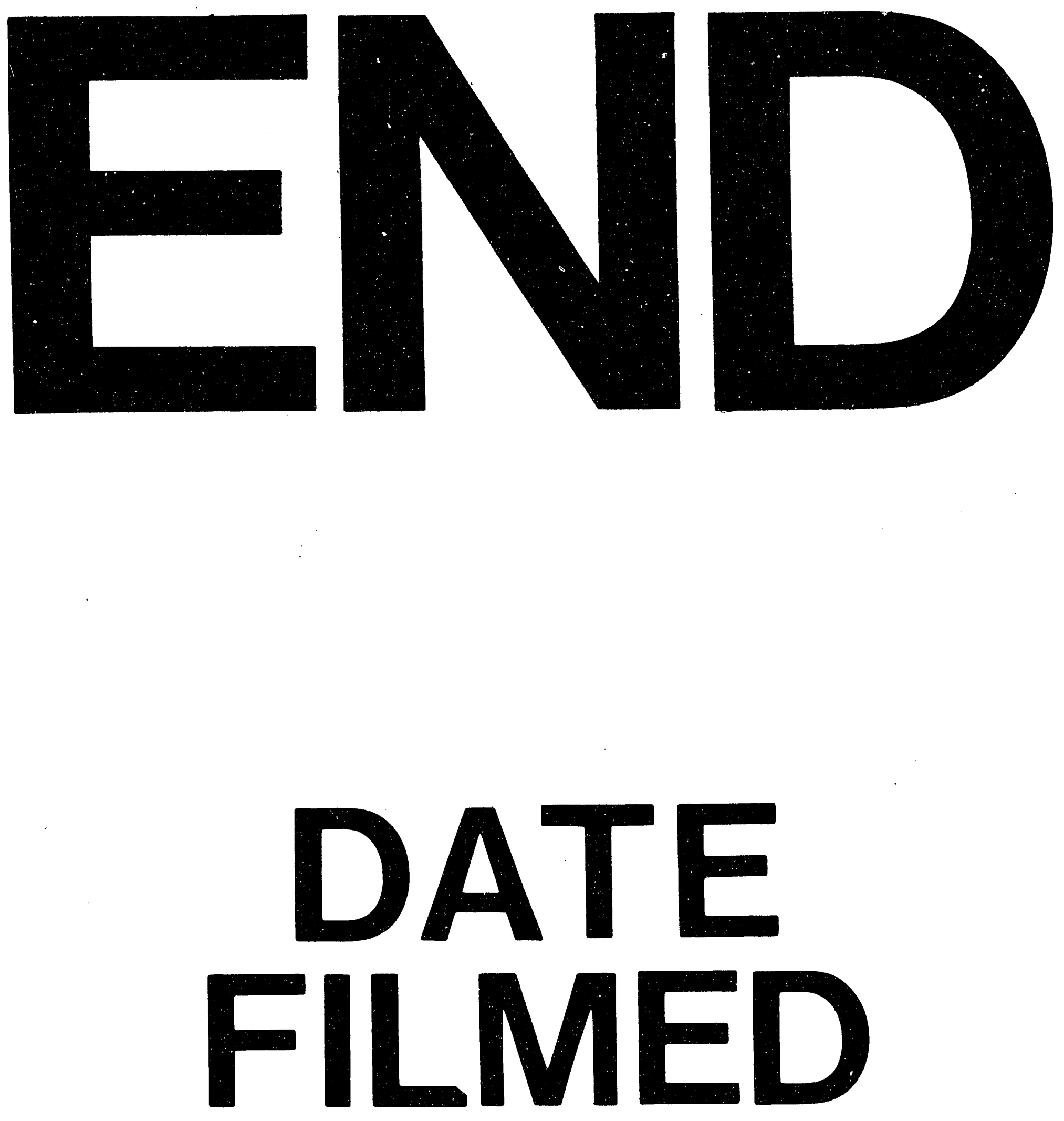

I

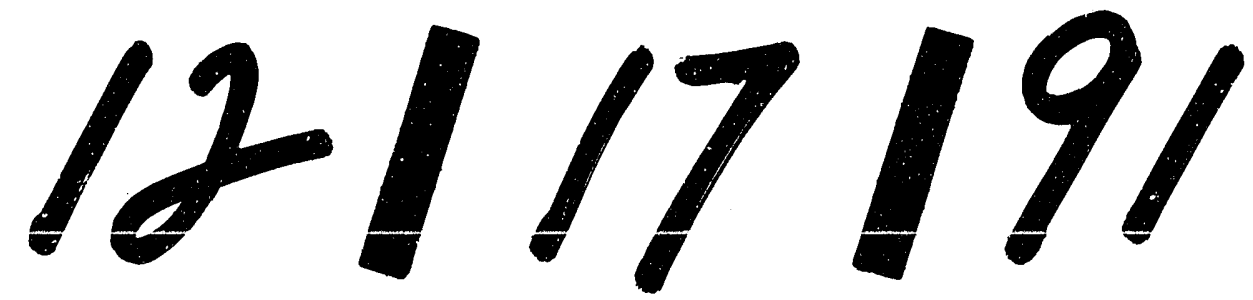


